\title{
Methodology to determine the apparent specific heat capacity of metal hydroxides for thermochemical energy storage
}

\author{
Daniel Lager ${ }^{1,4}(D) \cdot$ Wolfgang Hohenauer $^{1} \cdot$ Christian Knoll $^{2,3} \cdot$ Peter Weinberger $^{2} \cdot$ Andreas Werner $^{4}$
}

Received: 14 July 2017 / Accepted: 3 December 2017 / Published online: 11 December 2017

(c) The Author(s) 2017. This article is an open access publication

\begin{abstract}
Thermochemical energy storage uses reversible thermochemical reactions to store and release heat, representing a promising technology for energy conservation and utilizing fluctuating renewable energy sources and waste heat. Many recent studies have focused on determination of the enthalpy of reaction of possible thermochemical materials (TCM) based on thermogravimetric analysis (TGA) and differential scanning calorimetry (DSC). So far, comparatively few attempts have been made to characterize the apparent specific heat capacity at constant pressure $c_{\mathrm{p}}^{\mathrm{app}}(T)$ of the investigated TCM. The purpose of this study is to outline a measurement and analysis procedure to evaluate $c_{\mathrm{p}}^{\mathrm{app}}(T)$ of powdery TCM. The procedure is presented focusing on two metal hydroxides $\mathrm{Ca}(\mathrm{OH})_{2}$ and $\mathrm{Mg}(\mathrm{OH})_{2}$. Preliminary TGA experiments were conducted to identify reaction-free temperature intervals and mass change. Starting from the metal hydroxide, subsequent DSC experiments with two consecutive heating and cooling cycles were carried out to determine $c_{\mathrm{p}}^{\text {app }}(T)$ of the initial hydroxide and the oxide product. Three separate DSC runs for each candidate enable an evaluation of measurement uncertainty, and $c_{\mathrm{p}}^{\text {app }}(T)$ results were compared to available literature data. Preliminary TGA experiments have shown that the applied heating rate $\beta$ has a strong effect on the measured dehydration reaction. This result influences the consecutive $c_{\mathrm{p}}^{\text {app }}(T)$ interpretation of the metal hydroxides. Analysis of the measured $c_{\mathrm{p}}^{\text {app }}(T)$ data compared to literature show good agreement for both metal hydroxides and oxides. Overlapping endotherm effects, which are not part of $c_{\mathrm{p}}(T)$, have to be considered for further thermal conductivity calculations.
\end{abstract}

Keywords Thermochemical energy systems - Specific heat capacity - Thermochemical materials - Calcium hydroxide · Magnesium hydroxide

List of symbols

\section{Abbreviations}

TCES Thermochemical energy storage

TCM Thermochemical material

TGA Thermogravimetric analysis

Daniel Lager

daniel.lager@ait.ac.at

1 Center for Energy, AIT Austrian Institute of Technology $\mathrm{GmbH}$, Vienna, Austria

2 Institute of Applied Synthetic Chemistry, TU Wien, Vienna, Austria

3 Institute of Chemical, Environmental and Biological Engineering, TU Wien, Vienna, Austria

4 Institute for Energy Systems and Thermodynamics, TU Wien, Vienna, Austria
DSC Differential scanning calorimetry

TES Thermal energy storage

STES Sensible thermal energy storage

LTES Latent thermal energy storages

PCM Phase change material

LFA Laser flash apparatus

STA Simultaneous thermal analysis

MFC Mass flow controller

NBS National Bureau of Standards

\section{Symbols}

c Specific heat capacity $\left(\mathrm{J} \mathrm{kg}^{-1}-\mathrm{K}^{-1}\right)$

$T$ Temperature $\left({ }^{\circ} \mathrm{C}\right)$

$\beta \quad$ Heating or cooling rate $\left(\mathrm{K} \mathrm{s}^{-1}\right)$

$H \quad$ Enthalpy (J)

$h \quad$ Specific enthalpy $\left(\mathrm{J} \mathrm{kg}^{-1}\right)$

$m$ Mass (kg)

$p \quad$ Pressure $(\mathrm{Pa})$ 
$\lambda$ Thermal conductivity ( $\mathrm{W} \mathrm{m}^{-1} \mathrm{~K}^{-1}$ )

$a$ Thermal diffusivity $\left(\mathrm{m}^{2} \mathrm{~s}^{-1}\right)$

$\rho$ Density $\left(\mathrm{kg} \mathrm{m}^{3}\right)$

$U$ Voltage (V)

$\Phi$ Heat flow rate (W)

$t \quad$ Time (s)

$u \quad$ Standard uncertainty (1)

$n \quad$ Number of individual runs (1)

$k$ Coverage factor (1)

\section{Subscripts}

$\begin{array}{ll}\mathrm{p} & \text { At constant pressure } \\ \mathrm{t} & \text { Transition } \\ \mathrm{r} & \text { Reaction } \\ \mathrm{eff} & \text { Effective } \\ \mathrm{B} & \text { Bulk } \\ \mathrm{max} & \text { Maximum } \\ \mathrm{i} & \text { Initial } \\ \text { DSC } & \text { Differential scanning calorimetry } \\ 0 & \text { Zero line } \\ \mathrm{R} & \text { Reference } \\ \mathrm{S} & \text { Sample } \\ \mathrm{min} & \text { Minimum } \\ \mathrm{f} & \text { Final } \\ \mathrm{bl} & \text { Baseline } \\ \text { iso } & \text { Isotherm } \\ \mathrm{c} & \text { Combined }\end{array}$

\section{Superscripts}

app Apparent

\section{Introduction}

Decarbonization is an important keyword which is related to the climate change and global warming. As shown by Ervin [1], sustainable energy systems lead to a decrease in the production of carbon dioxide and other greenhouse gases. Thermal energy storage (TES) allows energy conservation which is needed to bridge the time gap between energy production and energy demand. This could be used to store heat due to overproduced energy coming from sustainable energy sources but also to reutilize waste heat from different processes.

According to [2], there are three core technologies for TES. The sensible thermal energy storage (STES) is currently the most common way to store heat. STES is utilizing the enthalpy change $\Delta H$ of a storage material due to the specific heat capacity $c_{\mathrm{p}}(T)$ and mass $m$ of the material and the prevailing temperature difference $\Delta T$. Latent thermal energy storages (LTES) use the phase transition enthalpy $\Delta H_{\mathrm{t}}$ of mainly solid-liquid but also solid-solid phase change material (PCM). TCES based on chemical reactions takes advantage of reaction enthalpies $\Delta H_{\mathrm{r}}$.

Reversible hydroxide reactions based on calcium hydroxide/calcium oxide and magnesium hydroxide/magnesium oxide for TCES application were already studied by Ervin [3] in 1977. In [4], the advantages and disadvantages of the two investigated hydroxides are described. Both of them show a high energy density and a good reversibility of the reaction. Additionally, they are nontoxic and the price is low which makes these two candidates very attractive for TCES applications. In [5], the authors did extensive thermal analysis on the hydration and dehydration reaction of $\mathrm{Ca}(\mathrm{OH})_{2}$ and $\mathrm{CaO}$. Measured quantities are reaction enthalpies, heat capacities, influence of the heating rate on dehydration temperatures, equilibrium temperatures and cycling stability. In the work of [6], the dehydration and hydration reaction of $\mathrm{Mg}(\mathrm{OH})_{2}$ and $\mathrm{MgO}$ were studied, focusing on cycling stability and dehydration temperatures. In the study of [7], equilibrium temperatures at a pressure of $p=10^{5} \mathrm{~Pa}$ and reaction enthalpies at $T=25^{\circ} \mathrm{C}$ for both hydroxides are defined as shown in Table 1 .

Nevertheless, although the reaction enthalpy $\Delta h_{\mathrm{r}}$ describes the heat which is consumed or released by the reaction, it is just one part of the enthalpy difference over a defined temperature range. For a detailed description of the enthalpy change $\Delta H$ in a TES application, further information about the actual specific heat capacity $c_{\mathrm{p}}(T)$ and of the current mass $m$ of educt and product is necessary:

$\Delta H=m_{1} c_{\mathrm{p} ; 1}(T) \Delta T_{1}+H_{\mathrm{r}}+m_{2} c_{\mathrm{p} ; 2}(T) \Delta T_{2}$

As described by Kalaiselvam and Parameshwaran [2], also a high thermal conductivity of a TCM is beneficial to reach fast charging and discharging cycles. For further investigations of the effective thermal conductivity $\lambda_{\text {eff }}$ in a packed bed configuration based on laser flash (LFA) experiments, the specific heat capacity $c_{\mathrm{p}}(T)$ and the bulk density $\rho_{\mathrm{B}}(T)$ are needed:

$\lambda_{\text {eff }}=a_{\text {eff }}(T) c_{\mathrm{p}}(T) \rho_{\mathrm{B}}(T)$

The intention of this paper is to focus on apparent specific heat capacity $c_{\mathrm{p}}^{\mathrm{app}}(T)$ measurements of the powdery hydroxide and oxide material. In the beginning, simultaneous thermal analysis (STA) is used to determine the specific reaction enthalpy $\Delta h_{\mathrm{r}}$ and characteristic temperatures for different heating rates $\beta$ of the dehydration reaction. Subsequent differential scanning calorimetry (DSC) in the identified temperature range on the hydroxide and oxide is shown and compared to available literature data. 
Table 1 Equilibrium temperatures and reaction enthalpies according [7]

\begin{tabular}{lll}
\hline Reaction & $T_{\text {eq }}$ at $p=10^{5} \mathrm{~Pa} /{ }^{\circ} \mathrm{C}$ & $\Delta h_{\mathrm{r}}$ at $T=25 /{ }^{\circ} \mathrm{C} / \mathrm{MJ} \mathrm{kg}$ \\
\hline $\mathrm{CaO}_{(\mathrm{s})}+\mathrm{H}_{2} \mathrm{O}_{(\mathrm{g})} \leftrightharpoons \mathrm{Ca}(\mathrm{OH})_{2(\mathrm{~s})}$ & 478.85 & 1.474 \\
$\mathrm{MgO}_{(\mathrm{s})}+\mathrm{H}_{2} \mathrm{O}_{(\mathrm{g})} \leftrightharpoons \mathrm{Mg}(\mathrm{OH})_{2(\mathrm{~s})}$ & 257.85 & 1.392 \\
\hline
\end{tabular}

\section{Materials and methods}

\section{Materials}

In the following measurements, calcium hydroxide from Merck with the name "Calciumhydroxid for analysis EMSURE ACS, Reag. Ph Eur" and magnesium hydroxide from Sigma-Aldrich with the product name "Magnesium hydroxide BioUltra, $\geq 99 \%$ (KT)" were analysed.

\section{Methods}

\section{Preliminary STA dehydration experiments}

A commercial STA with the product name NETZSCH STA 449 F5 (see Fig. 1) was used for thermogravimetric and calorimetric investigations. The system consists of a silicon carbide furnace which can handle a temperature range within 25 and $1600{ }^{\circ} \mathrm{C}$ with heating rates within 0.001 and $50 \mathrm{~K} \mathrm{~min}^{-1}$. The integrated balance has a weigh range up to $35 \mathrm{~g}$ with a resolution of $0.1 \mu \mathrm{g}$. All experiments used a TGA-DSC sensor with type $S$ thermocouples. Nitrogen is connected to the gas inlets, controlled by a mass flow controller (MFC).

In order to have accurate temperature and heat flow measurements, the used TGA-DSC sensor was calibrated with reference materials by analysing melting onset temperatures and melting enthalpies of pure metals according to [8]. The calibration experiments were conducted in cold welded aluminium crucibles with $\mathrm{In}, \mathrm{Sn}, \mathrm{Bi}$ and $\mathrm{Zn}$ in an inert nitrogen atmosphere with $\beta=10 \mathrm{~K} \mathrm{~min}^{-1}$.

For the STA experiments, aluminium crucibles were filled with the powdery sample material to the desired mass of $m \approx 10 \mathrm{mg}$. Aluminium has the advantage of a high thermal conductivity $\left(\lambda=236 \mathrm{~W} \mathrm{~m}^{-1} \mathrm{~K}^{-1}\right.$ at $T=0{ }^{\circ} \mathrm{C}$ [9] for pure aluminium) in comparison with aluminium oxide or platinum-rhodium crucibles. For the calorimetric measurements, it was decided to cover the aluminium crucibles with a pierced lid to reduce convection losses as compared to opened crucibles. Additionally, cold welded lids are used to avoid the possibility to leap up during the measurement. The pierced hole in the lid is necessary that evolved gases are able to escape from the sample crucible. Sample and crucible mass at room temperature are directly measured in the STA system prior the measurement runs.

The investigated metal hydroxide candidates show their dehydration reaction from the hydroxide to the respective oxide above room temperature at ambient pressure conditions. Thus, all STA experiments were started at ambient conditions. Three different heating rates with $\beta=2,5$ and $10 \mathrm{~K} \mathrm{~min}^{-1}$ were applied to identify the reaction-free temperature intervals. The maximum temperature $T_{\max }$ was adapted to the particular material with $550{ }^{\circ} \mathrm{C}$ for $\mathrm{Ca}(\mathrm{OH})_{2}$ and $450{ }^{\circ} \mathrm{C}$ for the $\mathrm{Mg}(\mathrm{OH})_{2}$.

For data analysis of STA results, the NETZSCH Proteus measurement and evaluation software were used.
Fig. 1 Left: NETZSCH STA 449 F5 measurement system; right: TGA-DSC-type $S$ sensor with aluminium crucibles and pierced lid
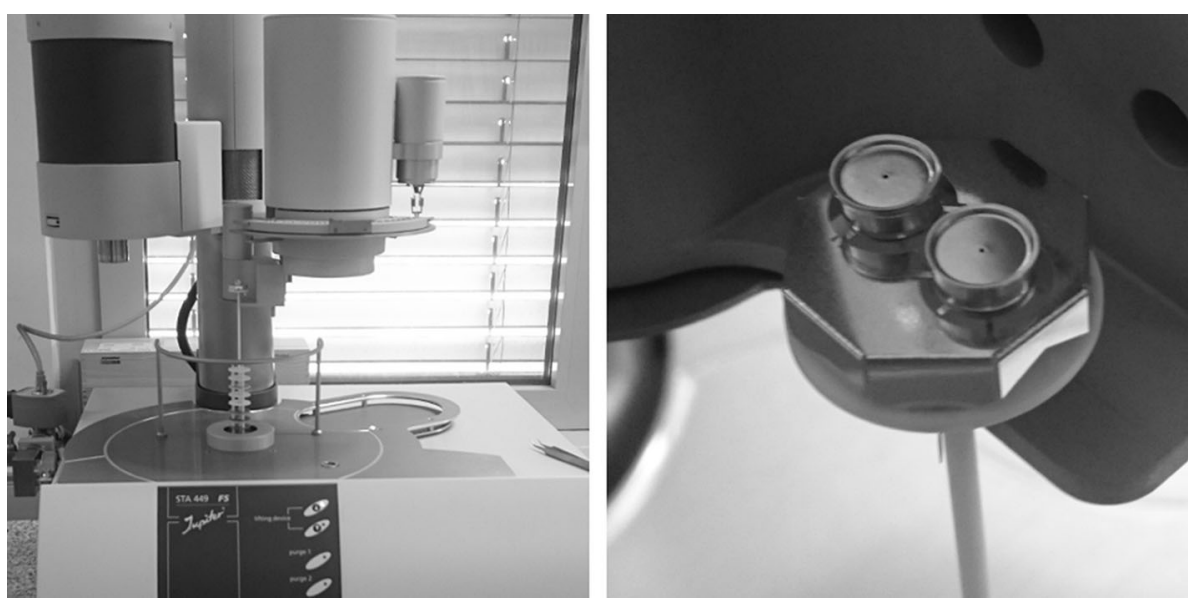
Measurement data of the balance and the DSC sensor can be directly loaded into the software, and mass change $\Delta \mathrm{m}$ / $m_{\mathrm{i}}$ and DSC sensor voltage $U_{\mathrm{DSC}}$ can be directly plotted versus temperature or time. The implemented software features allow calculating mass change steps, onset and peak temperatures, inflection points, etc. of the analysed TGA or DSC data. The software is based on the current international standards in the field of thermal analysis [8, 10-14].

The resulting heat flow $\Phi$ for a heat calibrated DSC sensor or peak area integration can be evaluated directly. For the calculation of the specific reaction enthalpy $\Delta h_{\mathrm{r}}$, the heat flow $\Phi$ is integrated over time $t$ between lower and upper integration limit defined by $t_{1}$ and $t_{2}$. The integration limits are connected with a linear baseline, and the heat flow $\Phi_{\mathrm{bl}}$ below this baseline is subtracted. The related mass $m$ is the mass before the reaction at $t_{1}$ at the initial temperature of the reaction $T_{\mathrm{i}}$.

$\Delta h_{\mathrm{r}}=\frac{\Delta H_{\mathrm{r}}}{m}=\frac{1}{m} \int_{t 1}^{t 2} \Phi-\Phi_{\mathrm{bl}} \mathrm{d} t$

\section{DSC procedure and data analysis for specific heat capacity evaluation}

For the determination of the apparent specific heat capacity $c_{\mathrm{p}}^{\mathrm{app}}(T)$ of the investigated $\mathrm{Ca}(\mathrm{OH})_{2} / \mathrm{CaO}$ and $\mathrm{Mg}(\mathrm{OH})_{2} /$ $\mathrm{MgO}$ samples, a commercial disc-type heat flow DSC NETZSCH DSC $204 F 1$ was used. The integrated furnace block covers a temperature range within -180 and $700{ }^{\circ} \mathrm{C}$ with heating rates between 0.001 and $100 \mathrm{~K} \mathrm{~min}^{-1}$ using a silver furnace for heating and liquid or gaseous nitrogen as cooling fluid. The implemented DSC sensor is based on type $\mathrm{E}$ thermocouples and placed in the centre of the furnace chamber. Two separate silver lids are used to close the furnace block after placement of the crucibles. To adjust the gas conditions during the measurement inside and outside the furnace block, two different gas inlets are available. A purge gas flows directly in contact with the DSC sensor and the crucible or sample, respectively, and a protective gas flows on the outside of the furnace block for protecting the system components from gaseous products from the sample. Both are controlled by a separate MFC.

The powdery $\mathrm{Ca}(\mathrm{OH})_{2}$ or $\mathrm{Mg}(\mathrm{OH})_{2}$ material is compacted and pressed into cylindrical samples to get good contact conditions between sample and the crucible bottom. The compaction of the samples increases the bulk density $\rho_{\mathrm{B}}$ and the overall sample mass $m$ in the crucible volume. Three samples per hydroxide were prepared and placed into aluminium crucibles with pierced and cold welded lid. Prior to this, weighing of the empty crucible with lid and the sample was performed to know the initial masses $m_{\mathrm{i}}$ of the crucible and the sample.

The used DSC sensor was calibrated with reference materials by analysing melting temperature onsets according [8] in order to have accurate temperature measurements. The temperature calibration experiments were conducted in cold welded aluminium crucibles with $\mathrm{C}_{10} \mathrm{H}_{16}$, In, $\mathrm{Sn}$ and $\mathrm{Zn}$ in a helium atmosphere with $\beta=10 \mathrm{~K} \mathrm{~min}^{-1}$.

A synthetic $\alpha-\mathrm{Al}_{2} \mathrm{O}_{3}$ sapphire (Standard Reference Material SRM 720) from the National Bureau of Standards (NBS) with the corresponding certificate served as reference material for the heat flow calibration of the DSC sensor. This certificate contains the enthalpy and heat capacity data within a temperature range of -263.15 and $1976.85^{\circ} \mathrm{C}$. The given heat capacity values have an accuracy in a range of $\pm 0.1-0.3 \%$ within the temperature range of $203.15-899.85^{\circ} \mathrm{C}$.

As shown in [15], helium is needed for DSC measurements below room temperature to ensure faster temperature stabilization in the measurement cell. Due to that, a constant helium gas flow of $40 \mathrm{~mL} \mathrm{~min}{ }^{-1}$ was used as purge and protective gas during the experiments.

The applied temperature programme for the DSC experiments started with a cooling segment to $T_{\min }=-50{ }^{\circ} \mathrm{C}$ using gaseous nitrogen as cooling agent for the furnace. After that, an isotherm segment prior to the heating with $t_{\text {iso }}=300 \mathrm{~s}$ was applied to achieve a stable DSC zero line. The heating segment used a heating rate of $\beta=10 \mathrm{~K} \mathrm{~min}^{-1}$ as recommended by Ervin [8]. Subsequently, the system is cooled down again to room temperature with $\beta=10 \mathrm{~K} \mathrm{~min}^{-1}$. The maximum temperature for the DSC runs was defined by the results of the preliminary STA experiments. For the evaluation of $c_{\mathrm{p}}^{\text {app }}(T)$, only the heating segment of the whole measurement sequence is used. Although the heating segment of the DSC experiments already starts at $-50{ }^{\circ} \mathrm{C}$, time is needed until a stable heating rate of $\beta=10 \mathrm{~K} \mathrm{~min}^{-1}$ is reached. Therefore, $T_{\min }$ for the evaluation of $c_{\mathrm{p}}^{\mathrm{app}}(T)$ is at $-30,20{ }^{\circ} \mathrm{C}$ higher than the programmed minimum temperature.

Under this defined conditions, nine consecutive DSC measurements per material consisting of three runs with empty crucibles (zero lines), three runs with the reference SRM 720 (reference), and three runs with three different samples of the same material were conducted. Figure 2 represents the procedure for $\mathrm{Ca}(\mathrm{OH})_{2}$.

Several zero line, reference and sample material DSC measurements are necessary to determine an expanded combined standard uncertainty $u_{\mathrm{c}}$ of the evaluated $c_{\mathrm{p}}(T)$. A software script was developed, which is able to load and evaluate $c_{\mathrm{p}}(T)$ and $u_{\mathrm{c}}$ over several DSC raw data files. As 
Fig. 2 DSC sensor voltage $U_{\mathrm{DSC}}$ of for the empty crucibles (zero line), SRM 720 (sapphire reference) and $\mathrm{Ca}(\mathrm{OH})_{2}$ up to $T_{\max }=550{ }^{\circ} \mathrm{C}$ with $\beta=10 \mathrm{~K} \mathrm{~min}^{-1}$

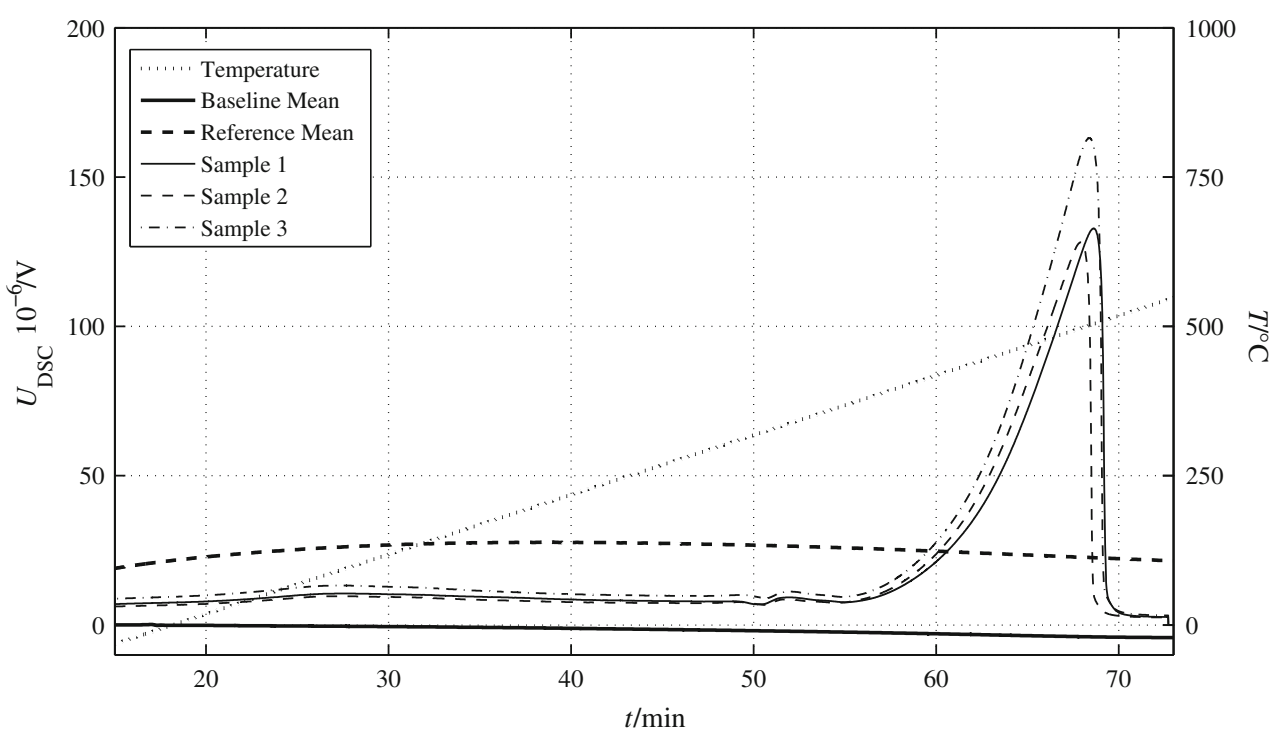

described in [11], $c_{\mathrm{p}}(T)$ is evaluated by the following equations. $U_{0, \mathrm{i}}(T)$ are the individual DSC signals of the empty crucibles or zero line measurements, $U_{\mathrm{R}, \mathrm{i}}(T)$ the individual DSC signals of the sapphire reference and $U_{\mathrm{S}, \mathrm{i}}(T)$ the individual DSC signals of the samples, $n_{0}, n_{\mathrm{R}}$ or $n_{\mathrm{S}}$ the number of individual runs for each measurement type, $c_{\mathrm{p}, \mathrm{R}}(T)$ the specific heat capacity of the reference sapphire, $m_{\mathrm{R}}$ the mass of the reference sapphire and $m_{\mathrm{S}, \mathrm{i}}$ the mass of the individual sample.

$\overline{U_{0}(T)}=\frac{1}{n_{0}} \cdot \sum_{i=1}^{n_{0}} U_{0, i}(T)$

$\overline{U_{\mathrm{R}}(T)}=\frac{1}{n_{\mathrm{R}}} \cdot \sum_{i=1}^{n_{\mathrm{R}}} U_{\mathrm{R}, \mathrm{i}}(T)-\overline{U_{0}(T)}$

$\overline{c_{\mathrm{p}, \mathrm{S}}(T)}=c_{\mathrm{p}, \mathrm{R}}(T) \cdot \frac{1}{n_{\mathrm{S}}} \sum_{i=1}^{n_{s}} \frac{m_{\mathrm{R}}}{m_{\mathrm{S}, \mathrm{i}}} \cdot \frac{U_{\mathrm{S}, \mathrm{i}}(T)-\overline{U_{0}(T)}}{\overline{U_{\mathrm{R}}(T)}}$

In the next step, the expanded combined standard uncertainty calculation based on the propagation of uncertainty with several sensitivity coefficients and a coverage factor of 2 according [16] is calculated with

$$
\begin{aligned}
& u_{\mathrm{c}} \cong k \cdot\left[\left(\frac{\partial c_{\mathrm{p}, \mathrm{S}}}{\partial \overline{U_{\mathrm{S}}(T)}}\right)^{2} \cdot u_{\mathrm{S}}^{2}+\left(\frac{\partial c_{\mathrm{p}, \mathrm{S}}}{\partial \overline{U_{\mathrm{R}}(T)}}\right)^{2} \cdot u_{\mathrm{R}}^{2}\right. \\
&\left.+\left(\frac{\partial c_{\mathrm{p}, \mathrm{S}}}{\partial c_{\mathrm{p}, \mathrm{R}}}\right)^{2} \cdot u_{\mathrm{cp}, \mathrm{R}}^{2}+\left(\frac{\partial c_{\mathrm{p}, \mathrm{S}}}{\partial \overline{U_{\mathrm{S}}(T)}}\right)^{2} \cdot u_{0}^{2}\right]^{0.5}
\end{aligned}
$$

where $k$ is the coverage factor, $u_{\mathrm{s}}$ the standard deviation of the sample measurements, $u_{\mathrm{R}}$ the standard deviation of the reference measurements, $u_{\mathrm{cp}, \mathrm{R}}$ the uncertainty given from the reference certificate and $u_{0}$ the standard deviation of the zero line measurements.

\section{Results and discussion}

\section{Dehydration reaction enthalpies and characteristic temperatures}

\section{Calcium hydroxide $\mathrm{Ca}(\mathrm{OH})_{2}$}

As shown in Fig. 3, the $\mathrm{Ca}(\mathrm{OH})_{2}$ TGA result shows a mass loss of $\Delta m / m_{\mathrm{i}}=-0.22$ over the whole temperature range. The repeatable mass loss of $\Delta m / m_{\mathrm{i}}=-0.01$ between $T=50-250{ }^{\circ} \mathrm{C}$ may be interpreted as desorption of adsorbed water. The applied heating rate $\beta$ has a strong effect on the evaluation of the measured dehydration temperatures. The lower integration limit to evaluate the dehydration reaction enthalpies was defined with a starting temperature of $250{ }^{\circ} \mathrm{C}$ for all heating rates. The upper integration limit depends on the actual final temperature $T_{\mathrm{f}}$ of the dehydration reaction. In case of $\beta=2 \mathrm{~K} \mathrm{~min}^{-1}$, the final temperature is defined with $T_{\mathrm{f}}=450{ }^{\circ} \mathrm{C}$, for $\beta=$ $5 \mathrm{~K} \mathrm{~min}^{-1}$ with $T_{\mathrm{f}}=480{ }^{\circ} \mathrm{C}$ and for $\beta=10 \mathrm{~K} \mathrm{~min}^{-1}$ with $T_{\mathrm{f}}=510^{\circ} \mathrm{C}$. The mass loss of $\Delta \mathrm{m} / \mathrm{m}_{\mathrm{i}}=-0.01$ between $T=50-250{ }^{\circ} \mathrm{C}$ before the dehydration reaction is added to the $\Delta m / m_{\mathrm{i}}=-0.01$ definition by Schaube et al. [5], leading to the evaluation of the dehydration temperature at $\Delta m / m_{\mathrm{i}}=-0.02$. A comparison of the temperatures at a defined mass loss of $\Delta m / m_{\mathrm{i}}=-0.02$ and specific reaction enthalpies $\Delta h_{\mathrm{r}}$ is shown in Table 2. 
Fig. 3 STA results for $\mathrm{Ca}(\mathrm{OH})_{2}$ using three different heating rates $\beta=10,5$ and $2 \mathrm{~K} \mathrm{~min}^{-1}$

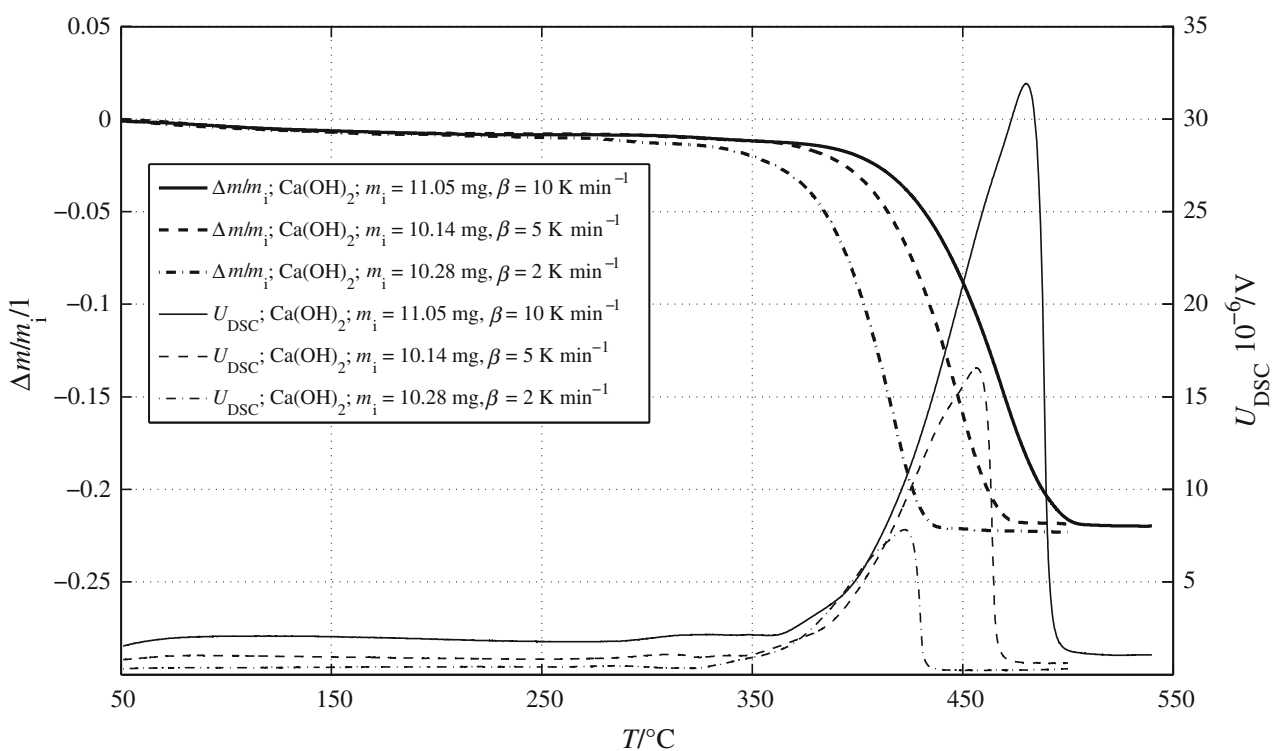

Table 2 Measured $\mathrm{Ca}(\mathrm{OH})_{2}$ dehydration temperatures and dehydration reaction enthalpies for $\beta=10,5$ and $2 \mathrm{~K}^{-1}$

\begin{tabular}{llll}
\hline & $\beta=2 \mathrm{~K} / \mathrm{min}^{-1}$ & $\beta=5 \mathrm{~K} / \mathrm{min}^{-1}$ & $\beta=10 \mathrm{~K} / \mathrm{min}^{-1}$ \\
\hline$T\left(\Delta m / m_{\mathrm{i}}=-0.02\right)$ & $350{ }^{\circ} \mathrm{C}$ & $385{ }^{\circ} \mathrm{C}$ & $400{ }^{\circ} \mathrm{C}$ \\
$\Delta h_{\mathrm{r}}\left(T_{\mathrm{i}}=250^{\circ} \mathrm{C}\right)$ & $1.240 \mathrm{MJ} \mathrm{kg}^{-1}$ & $1.258 \mathrm{MJ} \mathrm{kg}^{-1}$ & $1.261 \mathrm{MJ} \mathrm{kg}^{-1}$ \\
\hline
\end{tabular}

In [5], the evaluated onset temperature is described as the temperature where a mass loss or gain of $\Delta m$ / $m_{\mathrm{i}}=-0.01$ could be detected and describes temperatures between $T=293.7$ and $350.6^{\circ} \mathrm{C}$ for $\beta=0.03$ and $10 \mathrm{~K} \mathrm{~min}^{-1}$ according to this procedure. The measured dehydration temperatures are significantly higher than the reported values from [5]. Sample-specific attributes like the purity of the measured substances, particle size and bulk density but also setup-specific properties like crucible and sample geometry may influence the measured result. The measured specific reaction enthalpies $\Delta h_{\mathrm{r}}$ are lower as reported in [7] which may be attributed to the added sensible heat or enthalpy change starting from $T=25{ }^{\circ} \mathrm{C}$ up to the reaction temperature.

\section{Magnesium hydroxide $\mathrm{Mg}(\mathrm{OH})_{2}$}

Figure 4 represents the measured STA data for $\mathrm{Mg}(\mathrm{OH})_{2}$ with the heating rates $\beta=10,5$ and $2 \mathrm{~K} \mathrm{~min}^{-1}$ within a temperature range of $50-450{ }^{\circ} \mathrm{C}$. The TG result shows a mass loss of $\Delta m / m_{\mathrm{i}}=-0.28$ between the whole temperature range. A desorption phenomenon as described in [6] up to $150{ }^{\circ} \mathrm{C}$ could not be observed. The applied heating rate $\beta$ has a strong effect on the evaluation of the measured dehydration temperatures. The lower integration limit to evaluate the dehydration reaction enthalpies was defined with a starting temperature of $230{ }^{\circ} \mathrm{C}$ for all heating rates. The upper integration limit depends on the actual final temperature $T_{\mathrm{f}}$ of the dehydration reaction. In case of $\beta=2 \mathrm{~K} \mathrm{~min}^{-1}$, the final temperature is defined with $T_{\mathrm{f}}=375{ }^{\circ} \mathrm{C}$, for $\beta=5 \mathrm{~K} \mathrm{~min}^{-1}$ with $T_{\mathrm{f}}=400{ }^{\circ} \mathrm{C}$ and for $\beta=10 \mathrm{~K} \mathrm{~min}^{-1}$ with $T_{\mathrm{f}}=435^{\circ} \mathrm{C}$. A comparison of the temperatures at a defined mass loss of $\Delta m /$ $m_{\mathrm{i}}=-0.01$ and specific reaction enthalpies $\Delta h_{\mathrm{r}}$ is shown in Table 3.

In the work from [6], several isothermal experiments on the used $\mathrm{Mg}(\mathrm{OH})_{2}$ have shown that a full conversion to $\mathrm{MgO}$ can be reached at temperatures above $T_{\min }>300{ }^{\circ} \mathrm{C}$. In this work, based on dynamic heating segments in the STA experiments, dehydration starting at $T=280{ }^{\circ} \mathrm{C}$ could be observed for $\Delta m / m_{\mathrm{i}}=-0.01$ and $\beta=$ $2 \mathrm{~K} \mathrm{~min}^{-1}$. The measured specific reaction enthalpies $\Delta h_{\mathrm{r}}$ are lower as reported in [7] which may be again attributed to the added sensible heat or enthalpy change starting from $T=25^{\circ} \mathrm{C}$ up to the reaction temperatures. 
Fig. 4 STA results for $\mathrm{Mg}(\mathrm{OH})_{2}$ using three different heating rates $\beta=10,5$ and $2 \mathrm{~K} \mathrm{~min}^{-1}$

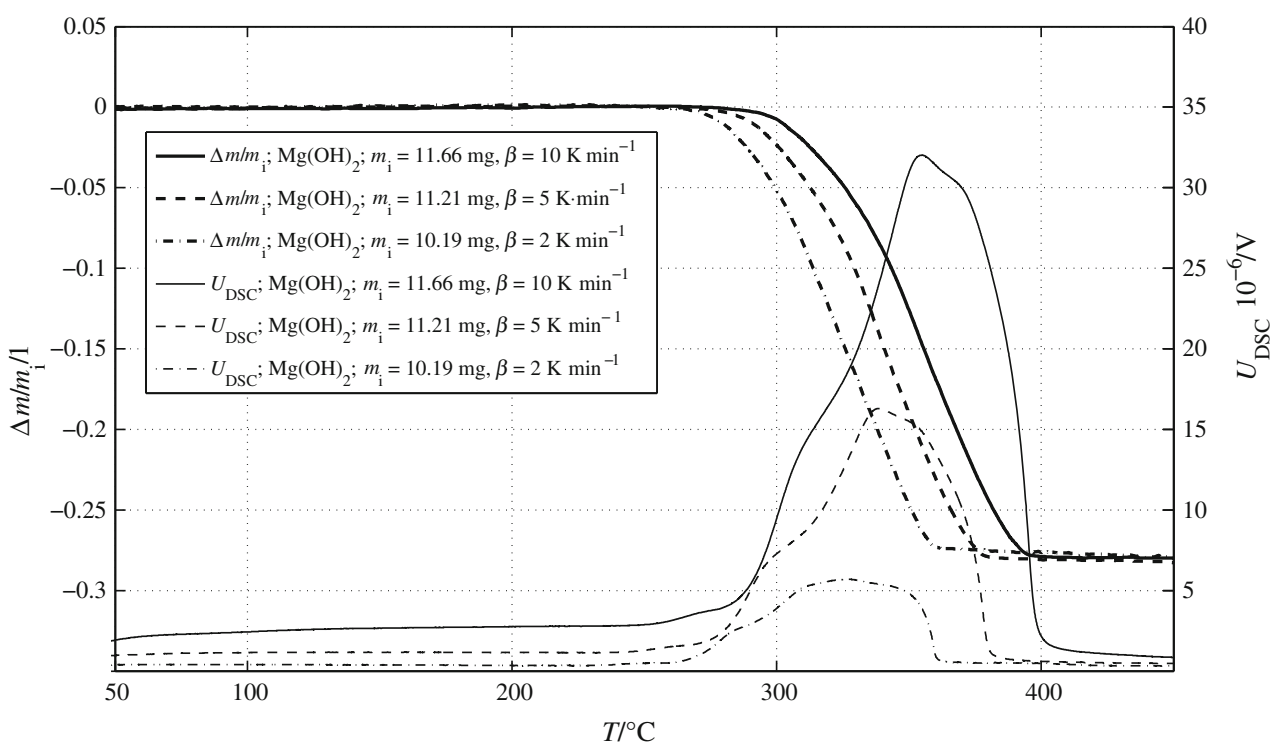

Table 3 Measured $\mathrm{Mg}(\mathrm{OH})_{2}$ dehydration temperatures and dehydration reaction enthalpies for $\beta=10,5$ and $2 \mathrm{~K} \mathrm{~min}^{-1}$ at $\Delta m / m_{\mathrm{i}}=-0.01$

\begin{tabular}{llll}
\hline & $\beta=2 \mathrm{~K} \mathrm{~min}^{-1}$ & $\beta=5 \mathrm{~K} \mathrm{~min}^{-1}$ & $\beta=10 \mathrm{~K} \mathrm{~min}$ \\
\hline$T\left(\Delta m / m_{\mathrm{i}}=-0.01\right)$ & $280{ }^{\circ} \mathrm{C}$ & $291{ }^{\circ} \mathrm{C}$ & $301{ }^{\circ} \mathrm{C}$ \\
$\Delta h_{\mathrm{r}}\left(T_{\mathrm{i}}=230{ }^{\circ} \mathrm{C}\right)$ & $1.220 \mathrm{MJ} \mathrm{kg}^{-1}$ & $1.266 \mathrm{MJ} \mathrm{kg}^{-1}$ & $1.278 \mathrm{MJ} \mathrm{kg}^{-1}$ \\
\hline
\end{tabular}

Fig. 5 Apparent specific heat capacity $c_{\mathrm{p}}^{\text {app }}(T)$ of $\mathrm{Ca}(\mathrm{OH})_{2}$ and $\mathrm{CaO}$

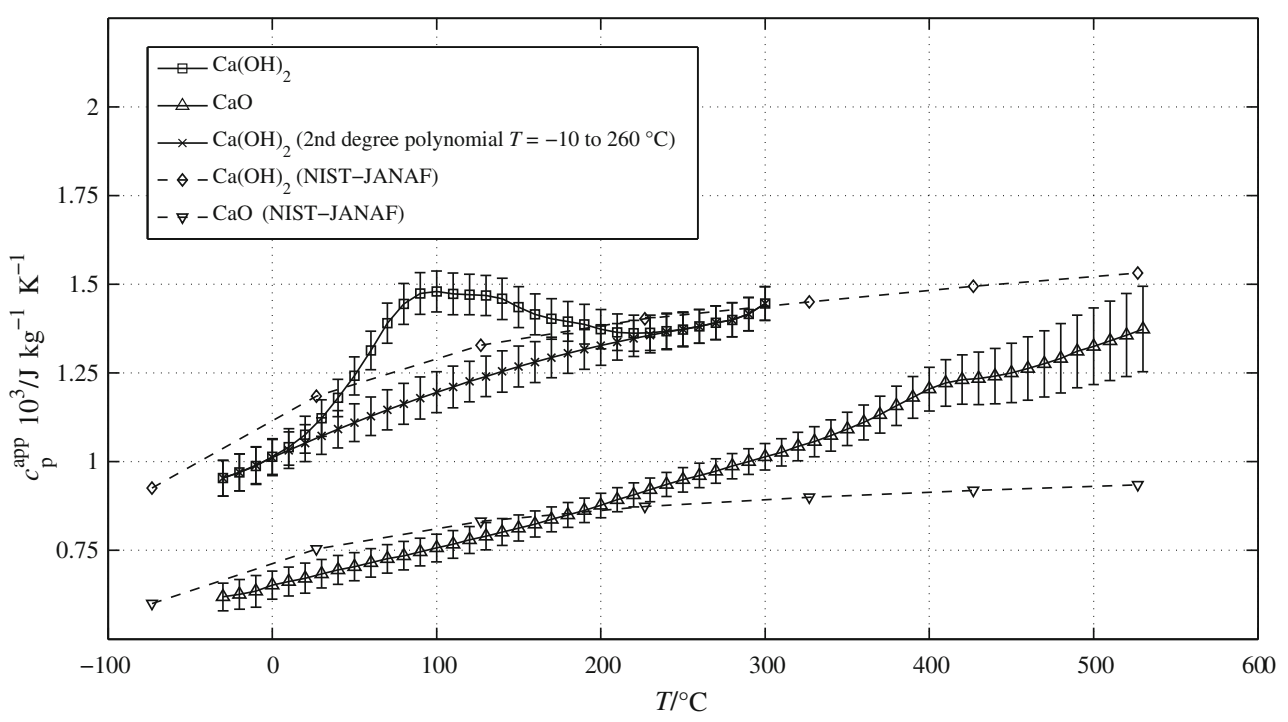




\section{Apparent specific heat capacity}

\section{Calcium hydroxide $\mathrm{Ca}(\mathrm{OH})_{2}$}

To analyse $c_{\mathrm{p}}^{\text {app }}(T)$ of $\mathrm{Ca}(\mathrm{OH})_{2}$ and $\mathrm{CaO}$, two consecutive heating cycles starting with $\mathrm{Ca}(\mathrm{OH})_{2}$ up to $T_{\max }=550{ }^{\circ} \mathrm{C}$ were conducted. The first heating cycle dehydrated the pure $\mathrm{Ca}(\mathrm{OH})_{2}$ to $\mathrm{CaO}$, and in the second heating cycle the DSC signal of the pure $\mathrm{CaO}$ was measured. After dehydration in the first heating cycle, the produced $\mathrm{CaO}$ sample has a different initial mass compared to the $\mathrm{Ca}(\mathrm{OH})_{2}$ precursor sample. For the $c_{\mathrm{p}}^{\text {app }}(T)$ evaluation, the initial mass $m_{\mathrm{i}}$ of $\mathrm{CaO}$ is determined through the preliminary TG measurement. According to the measurement shown in Fig. 3, the new $\mathrm{CaO}$ sample mass is calculated by reducing the $\mathrm{Ca}(\mathrm{OH})_{2}$ sample mass by $22 \%$.

In Fig. 5, the measured and evaluated $c_{\mathrm{p}}^{\mathrm{app}}(T)$ data and literature data from the NIST-JANAF data tables [17] are depicted. In the NIST-JANAF data tables, no explicit uncertainty for the specific heat capacity data for $\mathrm{Ca}(\mathrm{OH})_{2}$ and $\mathrm{CaO}$ is given.

Focusing on $\mathrm{Ca}(\mathrm{OH})_{2}$, the measured $c_{\mathrm{p}}^{\mathrm{app}}(T)$ shows a heat-consuming behaviour between -10 and $260{ }^{\circ} \mathrm{C}$ which is connected to a mass loss of $\Delta m / m_{\mathrm{i}}=-0.01$ up to $250{ }^{\circ} \mathrm{C}$ as shown in the TGA results in Fig. 3. This may be attributed to physically adsorbed water on the surface of the powder sample evaporating during the experiment. To eliminate this endothermic effect, a polynomial was used between -10 and $260{ }^{\circ} \mathrm{C}$. The evaluated $\mathrm{Ca}(\mathrm{OH})_{2}$ with the polynomial model and the NIST-JANAF data share a similar slope characteristic although NIST-JANAF data have slightly higher values over the whole temperature range. Considering the measurement uncertainties, a good comparability is given.
The $c_{\mathrm{p}}^{\mathrm{app}}(T)$ of $\mathrm{CaO}$ differs considerably from the NISTJANAF data. Considering the uncertainties, there is a good comparability between -30 and $250{ }^{\circ} \mathrm{C}$ but a deviation due to a completely different slope of the measured curve against the NIST-JANAF data at higher temperatures. Although the sample was not removed from the DSC cell between the $\mathrm{Ca}(\mathrm{OH})_{2}$ and $\mathrm{CaO}$ measurement, it appears to be again a dehydration starting at $350{ }^{\circ} \mathrm{C}$. This may be attributed to a rehydration of the sample in the cooling segment before the second consecutive heating started.

\section{Magnesium hydroxide $\mathrm{Mg}(\mathrm{OH})_{2}$}

Two consecutive heating cycles starting with $\mathrm{Mg}(\mathrm{OH})_{2}$ up to $T_{\max }=500{ }^{\circ} \mathrm{C}$ were conducted to analyse $c_{\mathrm{p}}^{\text {app }}(T)$ of $\mathrm{Mg}(\mathrm{OH})_{2}$ and $\mathrm{MgO}$. Dehydration STA experiments at $\beta=10 \mathrm{~K} \mathrm{~min}^{-1}$ have shown that full dehydration is reached at $T_{\mathrm{f}}=435^{\circ} \mathrm{C}$. After dehydration in the first heating cycle, the produced $\mathrm{MgO}$ sample has a different initial mass $m_{\mathrm{i}}$ compared to the $\mathrm{Mg}(\mathrm{OH})_{2}$ precursor. This is determined through the preliminary TG results from Fig. 4 and is calculated by reducing the $m_{\mathrm{i}}$ of $\mathrm{Mg}(\mathrm{OH})_{2}$ by $28 \%$.

Figure 6 shows the evaluated $c_{\mathrm{p}}^{\mathrm{app}}(T)$ data and available literature data from the NIST-JANAF thermochemical tables [17]. Again, for $\mathrm{Mg}(\mathrm{OH})_{2}$ and $\mathrm{MgO}$, no explicit uncertainty for the specific heat capacity data is documented in the NIST-JANAF data tables.

The measured $c_{\mathrm{p}}^{\mathrm{app}}(T)$ for $\mathrm{Mg}(\mathrm{OH})_{2}$ shows similar to the $\mathrm{Ca}(\mathrm{OH})_{2}$ measurements a heat-consuming behaviour within a different temperature range of $20-200{ }^{\circ} \mathrm{C}$. The preliminary STA experiment showed no mass loss in the TGA signal which may be attributed to the small initial weight $m_{\mathrm{i}}$ of the applied STA $\mathrm{Mg}(\mathrm{OH})_{2}$ samples. Again adsorbed water which is released might be a reason leading
Fig. 6 Apparent specific heat capacity $c_{\mathrm{p}}^{\text {app }}(T)$ of $\mathrm{Mg}(\mathrm{OH})_{2}$ and $\mathrm{MgO}$

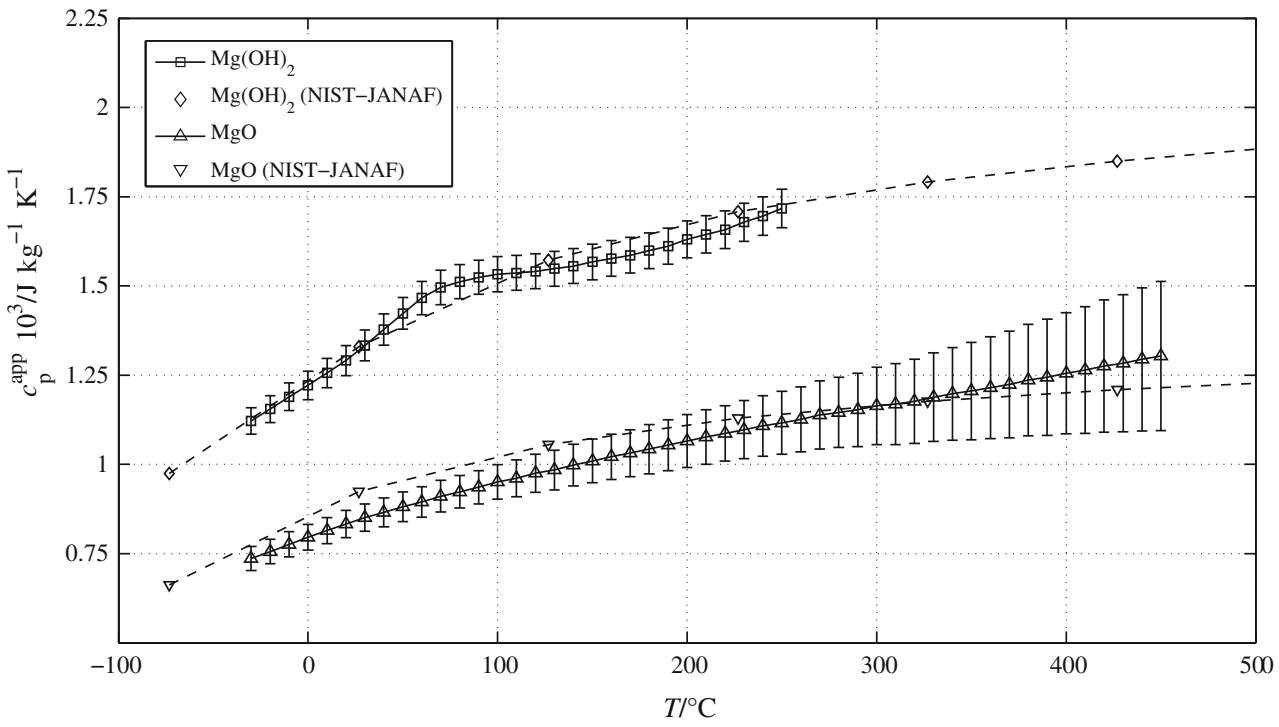


to the observed endothermic effect. Comparing the measured and the literature data from NIST-JANAF, one can see that they are nearly identical at temperatures below $20{ }^{\circ} \mathrm{C}$ and measurement uncertainties are overlapping above the observed endothermic effect.

The measured $c_{\mathrm{p}}^{\mathrm{app}}(T)$ for $\mathrm{MgO}$ shows slightly lower values as the NIST-JANAF data below $300{ }^{\circ} \mathrm{C}$. Comparing both curve characteristics, it can be seen that the slope of both curves is similar up to $200{ }^{\circ} \mathrm{C}$. As it can be seen from $\mathrm{Mg}(\mathrm{OH})_{2} \quad c_{\mathrm{p}}^{\mathrm{app}}(T)$ data, $T_{\max }$ was defined with $250{ }^{\circ} \mathrm{C}$ because at this temperature the dehydration heat is already part of the measured DSC signal. Due to that, it appears that the apparent $\mathrm{MgO}$ sample also has some $\mathrm{Mg}(\mathrm{OH})_{2}$ content which starts to dehydrate at $250{ }^{\circ} \mathrm{C}$.

\section{Conclusions}

STA experiments were used to determine the specific reaction enthalpy $\Delta h_{\mathrm{r}}$, characteristic temperatures $T$ at different heating rates $\beta$ for the dehydration reaction of $\mathrm{Mg}(\mathrm{OH})_{2}$ and $\mathrm{Ca}(\mathrm{OH})_{2}$. A temperature difference of $\Delta T=50{ }^{\circ} \mathrm{C}$ at a defined mass loss of $\Delta m / m_{\mathrm{i}}=-0.02$ for $\mathrm{Ca}(\mathrm{OH})_{2}$ and $\Delta T=21{ }^{\circ} \mathrm{C}$ for a defined mass loss of $\Delta m /$ $m_{\mathrm{i}}=-0.01$ for $\mathrm{Mg}(\mathrm{OH})_{2}$ could be observed. A specific dehydration reaction enthalpy of $\Delta h_{\mathrm{r}}=1.253 \mathrm{MJ} \mathrm{kg}^{-1}$ with an uncorrected sample standard deviation of $\sigma=$ $9.274 \mathrm{~kJ} \mathrm{~kg}^{-1}$ for $\mathrm{Ca}(\mathrm{OH})_{2}$ and $\Delta h_{\mathrm{r}}=1.255 \mathrm{MJ} \mathrm{kg}^{-1}$ with $\sigma=24.998 \mathrm{~kJ} \mathrm{~kg}^{-1}$ for $\mathrm{Mg}(\mathrm{OH})_{2}$ was evaluated.

Subsequent DSC experiments were realized to dehydrate $\mathrm{Ca}(\mathrm{OH})_{2}$ and $\mathrm{Mg}(\mathrm{OH})_{2}$ and to identify the apparent specific heat capacity $c_{\mathrm{p}}^{\mathrm{app}}(T)$ of the hydroxide and the oxide using the same sample. A method to calculate the expanded combined standard uncertainty of $c_{\mathrm{p}}(T)$ based on DSC measurements is shown. Differences between the measured $c_{\mathrm{p}}^{\mathrm{app}}(T)$ and literature data from the NISTJANAF thermochemical tables [17] are discussed.

This paper showed a methodology to determine the apparent specific heat capacity and the corresponding uncertainty based on STA and DSC measurements of commercial available powdery metal hydroxides. These results are needed to design a TES for specific applications based on the actual material. The measured results have shown that the determined specific heat capacity $c_{\mathrm{p}}(T)$ of the investigated materials is slightly lower than comparable literature data. Additional heat-consuming effects, which are not part of the specific heat capacity $c_{\mathrm{p}}(T)$ but represented as apparent specific heat capacity $c_{\mathrm{p}}^{\text {app }}(T)$, have to be considered outside the reaction temperatures of the TCM.

Acknowledgements Open access funding provided by TU Wien (TUW). The authors thank the Austrian Research Promotion Agency
(FFG) for the financial support of the project SolidHeat Kinetics (848876).

Open Access This article is distributed under the terms of the Creative Commons Attribution 4.0 International License (http://crea tivecommons.org/licenses/by/4.0/), which permits unrestricted use, distribution, and reproduction in any medium, provided you give appropriate credit to the original author(s) and the source, provide a link to the Creative Commons license, and indicate if changes were made.

\section{References}

1. Gil A, Medrano M, Martorell I, Lázaro A, Dolado P, Zalba B, Cabeza LF. State of the art on high temperature thermal energy storage for power generation. Part 1: concepts, materials and modellization. Renew Sustain Energy Rev. 2010;14:31-55. https://doi.org/10.1016/j.rser.2009.07.035.

2. Kalaiselvam S, Parameshwaran R. Thermal energy storage technologies for sustainability: systems design, assessment, and applications. 1st ed. London: Academic Press; 2014.

3. Ervin G. Solar heat storage using chemical reactions. J Solid State Chem. 1977;22:51-61. https://doi.org/10.1016/00224596(77)90188-8.

4. Pardo P, Deydier A, Anxionnaz-Minvielle Z, Rougé S, Cabassud M, Cognet P. A review on high temperature thermochemical heat energy storage. Renew Sustain Energy Rev. 2014;32:591-610. https://doi.org/10.1016/j.rser.2013.12.014.

5. Schaube F, Koch L, Wörner A, Müller-Steinhagen H. A thermodynamic and kinetic study of the de- and rehydration of $\mathrm{Ca}(\mathrm{OH})_{2}$ at high $\mathrm{H}_{2} \mathrm{O}$ partial pressures for thermo-chemical heat storage. Thermochim Acta. 2012;538:9-20. https://doi.org/10. 1016/j.tca.2012.03.003.

6. Pan Z, Zhao CY. Dehydration/hydration of $\mathrm{MgO} / \mathrm{H}_{2} \mathrm{O}$ chemical thermal storage system. Energy. 2015;82:611-8. https://doi.org/ 10.1016/j.energy.2015.01.070.

7. Felderhoff M, Urbanczyk R, Peil S. Thermochemical heat storage for high temperature applications-a review. Green. 2013; https://doi.org/10.1515/green-2013-0011.

8. DIN 51007. Thermal Analysis; Differential Thermal Analysis; Principles June 1994;71.040.40. Berlin: Beuth Verlag.

9. VDI heat atlas. 2nd ed. Heidelberg u.a.: Springer; 2010.

10. DIN EN ISO 11357-1. Plastics-Differential scanning calorimetry (DSC)_Part 1: General principles (ISO 11357-1:2016) February 2017;83.080.01. Berlin: Beuth Verlag.

11. DIN EN ISO 11357-4. Plastics-Differential scanning calorimetry (DSC)—Part 4: Determination of specific heat capacity October 2014;83.080.01. Berlin: Beuth Verlag.

12. DIN 51005. Thermal analysis (TA)-Terms August 2005;01.040.71; 71.040.99. Berlin: Beuth Verlag.

13. DIN 51004. Thermal analysis; Determination of melting temperatures of crystalline materials by differential thermal analysis June 1994;71.040.40. Berlin: Beuth Verlag.

14. DIN 51006. Thermal analysis (TA) - Thermogravimetry (TG)Principles July 2005;71.040.40. Berlin: Beuth Verlag.

15. Ehrenstein GW, Riedel G, Trawiel P. Praxis der thermischen Analyse von Kunststoffen. 2nd ed. München: Hanser; 2003.

16. JCGM. Guide to the expression of uncertainty in measurementJCGM 100:2008 (GUM 1995 with minor corrections-Evaluation of measurement data.

17. Chase MW. NIST-JANAF thermochemical tables. 4th ed. Woodbury: American Institute of Physics; 1998. 